\title{
Curatorial Crossover: Building Library, Archives, and Museum Collections
}

I TEND TO ASSOCIATE the word "crossover" with popular music. I think of crossovers as being those artists whose music has successfully crossed over from a smaller market to a bigger one, like Mexican musicians making it big in the United States, or black musicians making it big with white audiences. And I frankly love the idea that I, as a librarian, might be able to make a curatorial crossover into a bigger market, much as Ricky Martin or Otis Redding made a musical crossover.

Of course, I would have to address the two most common criticisms that are made of such crossover artists. First, that I had betrayed my roots-in my case, I suppose, that I had deserted librarianship to sing songs about archives or museums. And, second, that I had sold out and made a lot of money in the process. Nobody likes a rich and famous librarian. Nobody has ever met one either.

Maybe we should not go too far down this road. But it is interesting, I think, that the term "crossover" is really a marketing term. It describes a certain kind of market behavior. Do you think marketing might lie behind some of the recent discussion about a new convergence of libraries, archives, and museums? It may not always be convergence as much as rebranding. The Pierpont Morgan Library reopened in 2006 with a new name, The Morgan Library \& Museum. I guess it is a legitimate name change, given that it now has $50 \%$ more exhibition space. But I suspect that some suitably studied version of crossover theory was also part of the reason behind the change.

Perhaps some public or independent libraries or archives do need to piggyback onto the civic pride that has inspired such a strong burst of museum-building across America in the last decade. This burst might even be worth comparing to the library-building that was all the rage a century ago, when Morgan himself was active and culture was more readily identified with building community and literacy than with tourism and spectacle. But then I remember the success of the 
Seattle Public Library, or even the Internet Archive, and it makes me think that all three institutional labels can still hold their own in the marketplace: I suspect their relative values are only undergoing the usual currency fluctuations in a generally inflationary market.

\section{International Trends}

In the U.K. in the year 2000, the government set up a Museums, Libraries and Archives Council, explicitly linking for the first time the public funding of all three types of enterprise to a shared strategic direction. And, as Michelle Doucet points out in her article in this issue of $R B M$, the national library and national archives in Canada united two years ago to form Library and Archives Canada. Within my own subject area, architecture, I would point first to France's amalgamation of the Institut français d'architecture (IFA), the Musée des Monuments français, and the École de Chaillot—-the leading architecture school—into one giant so-called Cité de l'architecture et du patrimoine, which is due to open in Paris in Fall 2007. This will combine a library, archives, exhibition space, and an educational program into the largest architectural center in the world. I might also reference the celebration in London earlier this year of the transfer of the archives, prints, and drawings of the Royal Institute of British Architects (RIBA) to the Victoria and Albert Museum. These, I suggest, are only the most salient examples of two trends that are actually more prevalent outside than inside the United States. One trend is for the walls of libraries, museums, and archives to be more porous: their collections more open to being shared, transferred, sliced, and diced. And another trend is actually to amalgamate different types of institutions, responding to the common perception of a shared endeavor.

What I would like to do here is to probe a little deeper into these trends, particularly in relation to the physical collections under our care. I am not going to discuss building digital collections, since I take it for granted that porous walls and amalgamation work well for single-portal access. Rather, it is the effect of these trends on physical collections that concerns me more.

\section{Building Architectural Collections}

Nineteenth-century architects would have made little or no distinction among our various silos of libraries, archives, and museums. Architects have the instincts of magpies, taking inspiration from a vast number of likely and unlikely sources, and the institutions they formed reflect this tendency. The Anglo-Saxon tradition of the architectural center began when Sir John Soane bequeathed his house, museum, and library to the English nation in 1833, including a famously varied collection of antiquities, fragments, and furnishings, along with his books and the personal and 
professional archives he had produced or acquired over a lifetime of collecting. A year later, the Royal Institute of British Architects Library in London was formed. It rapidly acquired not only books, prints, and drawings, but also classical fragments, casts, specimens of stone and marble, as well as the usual medals, portraits, and busts. In 1868, William Ware founded the first institutional architecture library in the United States, at MIT. Seven years later he proudly reported that it consisted of 378 books, 2,705 photographs, 660 stereoscopic views, 250 glass slides, 810 drawings, 963 prints, 746 plaster casts, 35 specimens of stained glass, 32 architectural models, 95 lecture diagrams, and a miscellaneous amount of tiles, terra cotta, and other articles. He put all of these together in the same list as "materials of instruction."

Such tremendous variety in the public and private architectural collections of the nineteenth century gradually dissipated during the twentieth. What we would call museum materials typically were given or thrown away, while the archives department was expected to absorb everything left behind that lacked a title page. I am morally certain that it was a real disservice to the community when architectural librarianship became equated with the management of paper-based, printed collections. That could be the subject of a separate article. But the need to be rational and efficient that came with the growth of librarianship as a profession naturally propelled books and journals in one direction and the rest of this material in quite another.

\section{The Reverse Technological Barrier}

I believe that the historical separation of library materials from other research resources is irreversible. Yet the relationship between archives and museums still seems to me to carry a lot of potential. To illustrate this, I would like to describe a recent donation to Avery Library, an outstanding collection of architectural drawing instruments, dating from the early 18 th century onward. Although such a collection might well have ended up in a museum, at Avery it is now part of our archives and will be on semipermanent exhibition.

I accepted the collection because nobody in architectural schools or professional practice owns or uses such drawing instruments any more, and there is no convenient museum where students can be sent to study them. Consequently, a large number of Avery's core community of patrons simply does not know how the drawings and archives in our Drawings and Archives collection were produced. Surely this is a familiar story: evidence from material culture is needed now to compensate for a lack of general or technical knowledge being passed on from one generation to the next. This, it seems to me, is a key part in the new relationship between archives and museums - the result of what I call a "reverse 
technological barrier." Patrons are bringing more and more electronic technology into archives-laptops, digital cameras, handheld scanners, and the like—but the very portability and simplicity of these devices seems to cut them off from an increasingly alien environment of physical documentation. This is especially true in architecture, where no part of the training or practice of an architect today prepares him or her for the products of a paper-based office of thirty or more years ago. It can take a semester to get students to understand the status of a blueprint, and I imagine that other disciplines suffer from similar weaknesses in the chain of understanding.

My point is that when I accepted the generous gift of these drawing instruments, I was emphatically not seeking to expand Avery's mission but was simply looking for new ways to shore it up in a landscape transformed by new technologies. I decided to acquire museum pieces to support the understanding of archives. This is nothing new, of course: many rare book collections obtained printing presses for exactly the same reason. Nonetheless, the speed of technological change has increased the need for such importations.

\section{Invisible Archives}

Archives will increasingly benefit from the kind of interpretive environment that museum curators provide for their collections. Frankly, I also think that archives could use the kind of visibility that museums attract. In a worst-case scenario, physical archives are double victims of the new technologies. Not only is general understanding and appreciation of their material contents in decline, but also, thanks to better preservation techniques, processed archives are now typically stored in rows and rows of acid-free boxes and acid-free folders on inert gray metal shelving in climate-controlled storage. For conservation reasons, I am all in favor of this; but those of us who have to give guided tours to visitors and friends know that archives are not what you call "eye candy." They often look as if they have been guaranteed anonymity as part of a witness protection plan, which is a shame. For what goes on inside those boxes is often a far more riotous mix of material culture than anything a row of books or periodicals can provide. But in marketing terms, archives in storage suffer from an image problem.

My fears run deeper still, because I think the image problem can easily result in a true gap in understanding, at which point we really might lose physical archives to their digital surrogates. One of Columbia University's neighbors, Teachers College, has already decided to follow such a course: to dispose of its physical archives and accept only digital records. 


\section{System versus Program}

If I were to stay within my subject area, I would here again reference the Victoria and Albert Museum and its new "Architecture for All" gallery which opened in 2005 , and deals in a very interesting way with this image problem as it exhibits highlights from the RIBA archives now under its care. But although I think architecture has a good story to tell in our context, I will now focus on library materials.

I feel entitled to assume this means books, and similar stuff. One of the questions in Cathy de Rosa's wide-ranging OCLC report on Perceptions of Libraries (2005) was, "What is the first thing you think of when you think of a library?" Seventy percent of the respondents answered books. There was no runner-up-not even "microfilm" or "Internet connection." The great thing about books is that they are still a living part of our culture. Even if nobody really understands what a book is, at least everyone thinks he does, and I need not state the obvious to the readers of $R B M$ : that the book is a physical object and can be studied as a cultural artifact irrespective of its primary function as a communications tool.

But the fundamental difference, it seems to me, between libraries and museums is that libraries are all about systems, whereas museums are all about programs. We must remember, I think, that both the codex as a form and publishing as an enterprise have always (and increasingly) allowed books and periodicals to reach out and embrace the systems we librarians impose on them. It is sheer hubris on the part of librarians to believe they organize knowledge. They do not. Archivists do that, and museum curators do that, but librarians do not. Librarians just apply various systems to preorganized knowledge and then answer questions about what they have done. Libraries are repositories of systematized knowledge, and their historical material constituents bear all the signs of the system, internally and externally: internally, thanks to the invention of the title page, the imprint, the index, the copyright statement, the cataloguing-in-publication data, and so on; and externally, in their standard sizes, standard bindings, and standard spine titles. Books, unlike most commercial products, are still designed to be placed conveniently alongside one another, thin side out, without losing their identity. In such ways, the codex and its publishers have reached out to us, the systematic librarians, who gleefully complete the task with our library bindings, barcodes, sticky spine labels, and secret security devices. We make very sure that the inhabitants of our gated communities stay part of our system.

In brief, libraries impose systems in and on their materials while museums, by contrast, build exhibition and educational programs around their materials. Looking at

1. Cathy de Rosa, Perceptions of Libraries (Dublin, Ohio: OCLC, 2005), p. 31. 
the consequences of this difference will make us hesitate before embarking on our curatorial crossover.

\section{Museums of the Book}

Am I correct in assuming that rare book librarians are on the defensive in this scenario, feeling the need to find new arguments for spending time and money on old books in an age when all the world's knowledge is being targeted for scanning and distribution in a searchable format? I have just read a Digital Libraries Foundation report that states that Google has already digitized 500,000 books, with another $1,000,000$ possible before the end of 2006 , and at least $10,000,000$ certain to be scanned within the next five years. Even the restrictions imposed by current copyright law might break under the weight of such statistics, and that does not include the efforts of Amazon, the Open Content Alliance, and other mass digitization projects.

So is the Internet now our library, and the book stacks our museum? My answer is "no"-at least I hope not. As a basis for my answer, I would like to commandeer Thomas Tanselle's brilliant 1990 lecture at Columbia University for the Book Arts Press, which some of you may know, on Libraries, Museums, and Reading. As Tanselle notes, "A respect for the physical evidence in books becomes as central to an appreciation of verbal works as is a respect for the physical objects in museums to an appreciation of visual art."”

Now you and I would probably agree that, in the words of that great crossover song, when it comes to the physical evidence in books, all we need "is a little respect." But where can we get it? In a world of mass digitization, how can we possibly generate respect among our core community, let alone the larger external communities that will actually decide the fate of our collections? After all, is that not what we are trying to do when we toy with the idea of declaring our rare book collections "museums of the book"?

If so, I think we are making a mistake, and Tanselle identifies the reason why it is a mistake. "The primary fact about the nature of libraries — and the one most often ignored - is that libraries do not house works of literature or other verbal works. Language is intangible: works that use language as their medium are inevitably intangible also: and one cannot preserve something that is intangible in a physical space."”

Tanselle points out precisely why book collections cannot be considered purely museum collections, even though their physical evidence should be valued as highly. If

2. G. Thomas Tanselle, Libraries, Museums, and Reading, Sol. M. Malkin Lectures in Bibliography, No. 6, 1990 (New York: Columbia University School of Library Service, 1991), p. 19.

3. Ibid., p. 16. 
we cannot preserve the intangible work in a physical space, then we certainly cannot exhibit it in a physical space either. And if we cannot preserve or exhibit a work in space, then I just do not see how it can be regarded as a museum object.

In the everyday dualism of our lives, exhibited books are time translated into space; they are cognition translated into recognition. No amount of gazing at Shakespeare's first folio will convey its intangible value unless we have already read Shakespeare. When it comes to books, the exhibition experience is highly dependent on the visitor making analogies with his or her own prior experience. In fact, I would argue that an exhibited book can hold up a mirror to the viewer's imagination, but for everything else it relies on the quality of the labeling and the catalog. The illustrated book is arguably a different case, but in many ways only because the opportunity for misunderstanding it is greater. In any case, curatorially speaking, I would be loathe to argue that illustrated books are museum worthy while leaving their unillustrated cousins something less than that.

\section{Art Properties}

I am wrong, of course, to identify museums with exhibitions so simplistically. Collecting museums are centers for historical research that may well decide to collect materials without any intention to exhibit them. Surely, however, such collections do not in themselves constitute a museum, even if they are made available to scholars and other interested parties. I think of museums as being created for and open to a variety of publics rather than a series of individuals. This, I think, is what distinguishes them from a fourth kind of collection-the one that is missing from our triumvirate of libraries, museums, and archives. I am referring to the storehouse, or what I would call the Department of Art Properties.

Departments of art properties are fairly common on university campuses; and, as the Avery Librarian, I have administrative responsibility for the one at Columbia University. This department looks after everything owned by the university that has a claim to the status of art that is not already looked after by one of Columbia's libraries. It covers everything from campus sculptures to portraits of deans to ancient pots to portfolios of photographs. At Columbia, art properties may circulate to serve the advanced research needs of faculty, or they may just cheer up a corridor. Nevertheless, the majority of items stay put in closed access storage with minimal documentation and even less funding.

\section{Book Properties}

I am seriously worried that art properties may represent a near equivalent for the fate of our rare book collections if we decide to overemphasize the artifac- 
tual value of the latter. In other words, I think that to take aim at a definition of books - even rare books - as museum objects would risk having the arrow fall considerably short of its target. If my experience at Columbia is anything to go by, such a Department of Book Properties would then become an inferior sister of the already underappreciated, underfunded, and largely invisible art properties department.

We might still invite a tenured professor to come and pick out a few books from time to time, to decorate his argument, or his office. But, in effect, we will have condoned the severance of the message from the medium, the intangible from the tangible, and thereby condemned the physical object to sadly marginal realms.

In fact, we have already built remote storage facilities for just such a fate. To complete the picture, we need only to cut the book delivery systems in favor of a digitization on demand to fulfill patron requests. There is an obvious connection here with the fate of the invisible archives. It is, of course, also the old fate of rare books that nobody is allowed to look at when microfilm copies are available in their stead.

\section{Access with Adjectives}

I have tried to argue that discussions of curatorial crossovers should not ignore the physical materials under our care, digital projects notwithstanding. I have pointed out that archives, in particular, are increasingly vulnerable to neglect through misunderstanding, and that museum techniques might help prevent this. Yet I have cautioned against treating books, even rare books, as museum objects because I think they risk losing too much by that treatment.

I wish I could have come to a more radical conclusion. I take it as a fact that books generally fail as museum objects, just as museum objects generally fail as library materials. This may still leave rare book curators on the defensive, but I am personally convinced that we should not—and indeed must not—give up the practice of collecting rare books for their intellectual and emotional value.

I say this because we know what the rest of the world does not, namely that scanning a book does not actually provide access to it. It only provides a kind of access to a new kind of surrogate. I fear that librarians and curators are collectively in danger of trying to debate the issue of mass digitization without using the right qualifiers.

Let me make a plea for more precision. What we probably mean in our discussions about new technologies for access is enhanced visual and functional access to a digital surrogate. This is fine, but it is access with adjectives, by which I mean it is a form of 
access, a qualified access. Digitization is very good at skimming off the intentional layer of a book's content, and it can produce a surrogate for some of a book's visual aspects. The digital representation can then provide dramatically enhanced access to what it has captured, through full-text searching, zoom features, and so on. But it leaves behind all the rest of that book's potential contribution to the world of knowledge: its provenance, its design, its weight, its size, its color under different light, its smell, its texture, its materials, its watermarks, its structure, its binding, its evidence of age, its evidence of use, its evidence of misuse. Who will take the time to sweep up all the potential knowledge that is left scattered on the scanning room floor? And who will know what do with it? Never mind that, when a single individual copy is digitized, it immediately becomes first among equals, and a defective copy or an error in scanning becomes enshrined in scholarship.

\section{Empathetic Access}

Finally, I want to make an unashamed plea for the emotional value of rare book collections, what I would call empathetic access. Digital versions and exhibitions alike cut us off from the empathetic access granted by opening, holding, sifting through what the original author opened, held, sifted through - the physical link of sitting down to read what he or she sat down to write. I am referring, of course, to the emotional link that likely drew us to become rare book librarians in the first place. What, after all, is the first thing we do, sitting in the rare book reading room, when we are delivered the earliest surviving manuscript of some great writer, or last recording? I think what most of us do first is to recover from our emotions.

I would like to end by quoting from another presentation given at Columbia University, this time in 1941, by then librarian of the University of Michigan's Clements Library, Randolph G. Adams:

The builder of the rare-book library is like the pioneer, the pathfinder, the explorer. He wants to contemplate what few, if any, have ever experienced before. His satisfaction is largely emotional, rather than intellectual. ... The readers in rare-book libraries are likely to be persons who are trying decently to cultivate or to express the sentimental or emotional aspects of their being. Sometimes I think they are trying to express something which is beyond the limitations of poetry or music. ${ }^{4}$

I believe it is more important now than ever before that we build this sentiment into our collection development campaigns.

4. Randolph Adams, Who Uses a Library of Rare Books? (New York: Columbia University Press, 1941), p. 20. 